\title{
Cardio-oncology for the 21st century: introduction.
}

\author{
Marc L Schwartz, MD \\ Thomas Jefferson University
}

Follow this and additional works at: https://jdc.jefferson.edu/cardiologyfp

Part of the Cardiology Commons

Let us know how access to this document benefits you

\section{Recommended Citation}

Schwartz, MD, Marc L, "Cardio-oncology for the 21st century: introduction." (2013). Division of Cardiology Faculty Papers. Paper 23.

https://jdc.jefferson.edu/cardiologyfp/23

This Article is brought to you for free and open access by the Jefferson Digital Commons. The Jefferson Digital Commons is a service of Thomas Jefferson University's Center for Teaching and Learning (CTL). The Commons is a showcase for Jefferson books and journals, peer-reviewed scholarly publications, unique historical collections from the University archives, and teaching tools. The Jefferson Digital Commons allows researchers and interested readers anywhere in the world to learn about and keep up to date with Jefferson scholarship. This article has been accepted for inclusion in Division of Cardiology Faculty Papers by an authorized administrator of the Jefferson Digital Commons. For more information, please contact: JeffersonDigitalCommons@jefferson.edu. 


\title{
As submitted to:
}

\author{
Seminars in Oncology
}

\section{And later published as:}

\section{Cardio-oncology for the 21st Century: Introduction \\ Volume 40, Issue 2, Pages: 145-146, April 2013 \\ DOI: 10.1053/j.seminoncol.2013.01.011}

INTRODUCTION

Marc L. Schwartz MD

Clinical Associate Professor of Medicine

Division of Cardiology

Jefferson Medical College

Thomas Jefferson University

Suite 1518

1015 Chestnut Street

Thomas Jefferson University Hospital

Philadelphia, PA 19107

215-955-8706 
215-955-8509 (fax)

marc.schwartz@jeffersonhospital.org

No financial support.

I have no conflict of interest or competing financial or personal relationships that could inappropriately influence the content of this article.

\section{Cardio-Oncology for the 21st Century: Introduction}

Based on the latest statistics the prognosis for patients with malignancy has dramatically improved. The overall 5 year survival rate for those who were diagnosed with a cancer between 2002 and 2008 was approximately $65 \%{ }^{1}$, and as of 2008, 12 million Americans were cancer survivors. ${ }^{2}$ However, this extended longevity now exposes these patients to the risk of other health issues related to their primary cancer or to the treatment that ensured their survival. Specifically, patients who have not succumbed prematurely to their oncologic disease may develop cardiovascular disease that is either a result of the long-term effects of their traditional cardiovascular risk factors or that is due to the direct cardiovascular toxicity of the cancer itself or from the administered therapy. In fact, Patnaik and colleagues reviewed the Surveillance, Epidemiology, and End Results (SEER)Medicare linked database and found that breast cancer survivors were as likely to die from cardiovascular disease as from recurrent breast cancer. ${ }^{3}$ Additionally, Mertens and colleagues found that cardiovascular events are the leading cause of nonmalignant deaths in survivors of childhood cancers. ${ }^{4}$ 
Because of the ongoing need for recurrent cancer monitoring, the treating oncologist may be the de facto primary care physician for many oncologic patients. Also, the treating oncologist is the most knowledgeable physician with regard to the possible toxicities related to a patient's cancer and any administered therapy. Therefore, in addition to monitoring these patients for recurrent oncologic disease, it is the treating oncologist's responsibility to be cognizant of other long-term health complications to which these patients are susceptible. This special edition of Seminars in Oncology reviews the cardiovascular issues that can arise during the ongoing care of oncologic patients.

Cardiovascular disease assessment begins with a careful history that includes questions about the presence of symptoms that may not be part of the usual review of systems associated with cancer patients. A change in exercise tolerance either due to chest/neck/shoulder discomfort or dyspnea, complaints of near- syncope or syncope, feelings of rapid or irregular palpitations, or an awareness of peripheral edema or pulmonary congestion may be indicators of cardiac decompensation. Additionally, in order to complete the cardiovascular history, the presence of known risk factors - hypertension, hyperlipidemia, diabetes, physical inactivity, significant family history, and tobacco/alcohol usage—should be assessed.

During a cancer patient's physical examination, the oncologist needs to include a careful evaluation of the cardiovascular system, including the measurement of 
accurate vital signs (blood pressure should be obtained with the arm held at heart level while the patient is sitting on a chair, feet on the floor, after 5 minutes of relaxation ${ }^{5}$ ), assessment of the jugular venous pressure, auscultation for the presence of arterial bruits as well as for cardiac murmurs, gallops, and rubs, and observation for signs of hypervolemia (e.g., pulmonary congestion, edema, ascites, hepatic congestion).

Based on this history and physical examination, a cancer patient may require further cardiac tests such as electrocardiograms, echocardiograms, nuclear imaging scans, and biomarker measurements. Depending upon the level of the patient's risk and the complexity of the issues involved, co-evaluation with a cardiologist familiar with these cardio-oncologic issues may be appropriate. Davis and Witteles review strategies for cardiac testing in cancer patients at high risk of cardiac complications. In order to assess and treat the long-term risk of developing cardiac disease in cancer survivors, Carver et al propose a comprehensive diagnostic and therapeutic strategy.

Although cardiovascular toxicity including left ventricular systolic dysfunction, heart failure, hypertension, coronary ischemia, pericardial disease, and arrhythmias may develop from all of the classes of cancer therapy, a variety of cancers themselves may adversely affect the cardiovascular system as well. Bonita and Pradhan review the possible toxicities of the chemotherapeutic agents, while Ryberg discusses the cardiac concerns related to treatment with the biologic agents. The 
cardiotoxic effects of radiation therapy are discussed by Martinou and Gaya.

Regarding cancer-induced cardiac toxicity, Lenihan et al review the evaluation and management of infiltrative cardiomyopathies and pericardial disease.

Rather than only identifying patients who may have developed overt cardiac toxicity from their cancer-related disease, the ultimate goal for both the oncologist and the cardiologist is to prevent the development of these complications. Cardinale et al review the literature with regard to promising strategies in this area and share the available data regarding treatment options.

In addition to the insults that occur to the cardiovascular system as a result of a patient's cancer or their cancer treatment, a patient's oncologic status may also be affected by their preexisting cardiovascular disease. Many cancer patients will already be maintained on the kind of complex cardiovascular drug regimen that has led to improved survival among cardiac patients. Chen and Parameswaran review how these cardiac agents will affect a cancer patient's clinical status and therapeutic treatment options.

Given the interplay between oncologic and cardiac disease states, Jones et al explore the risk factors common to both of these conditions and demonstrate the data that support a preventive treatment strategy, including exercise, that might be effective in decreasing the incidence of both cancer and cardiac disease. 
In an era when more effective detection and treatment of both oncologic and cardiovascular disease states are available, it is incumbent upon treating physicians to be aware of the complicating issues that may negatively impact the prognosis of these patients. More outcomes data is needed to guide specific care recommendations, but in the meantime, close consultation between oncologists and cardiologists is required for the optimal management of patients who have, or who are at risk for developing, cardio-oncologic disease.

\section{References}

1. Howlader N, Noone AM, Krapcho M, Neyman N, Aminou R, Altekruse SF, et al (eds). SEER Cancer Statistics Review, 1975-2009 (Vintage 2009 Populations), National Cancer Institute. Bethesda MD, http://seer.cancer.gov/csr/1975 2009 pops09/, based on November 2011 SEER data submission, posted to the SEER web site, April 2012.

2. Am Cancer Society. Cancer Facts and Figures. 2012 Atlanta: American Cancer Society;2012.

3. Patnaik JL, Byers T, Di Guiseppi C, Dabelea D, Denberg TD. Cardiovascular disease competes with breast cancer as the leading cause of death for older females diagnosed with breast cancer: a retrospective cohort study. Breast Cancer Res. 2011;13:R64. 
4. Mertens AC, Liu Q, Neglia JP, Wasilewski K, Leisenring W, Armstrong GT, et al. Cause -specific late mortality among 5-year survivors of childhood cancer: the Childhood Cancer Survivor Study. J Natl Cancer Inst 2008;100(19):136879.

5. Chobanian AV, Bakris GL, Black HR, Cushman WC, Green LA, Izzo JL Jr, et al. $7^{\text {th }}$ Report of the Joint National Committee on Prevention, Detection, Evaluation, and Treatment of High Blood Pressure: the JNC 7report. JAMA 2003May21;289:2560-72. 
